\title{
PRESENTACIÓN DE LA CLASE MARGINAL O EL OTRO en los cuadros de costumbres de José Victoriano Betancourt y Daniel Mendoza
}

\author{
JENIFFER FERNÁNDEZ HERNÁNDEZ \\ Florida International University
}

Recepción: 7 de abril de 2020 Aceptación: 25 de junio de 2020

Resumen: Es el propósito de este artículo examinar y comparar la proyección del personaje marginal en el costumbrismo cubano y venezolano del siglo XIX, de ese otro que forma parte de los sectores marginalizados y vive en las fronteras de la civilización. Para esto se estudian los cuadros de costumbres Los curros del Manglar o el triple velorio de José Victoriano Betancourt y Un llanero en la capital y Palmarote en Apure de Daniel Mendoza. Intento argumentar que los proyectos específicos que propone la clase letrada decimonónica para la construcción de cada nación — bien sea la campaña higienista o la aceptación de los aportes rurales - termina afectando el retrato de los personajes marginales en las letras costumbristas de ambos países.

Palabras clave: costumbrismo, Daniel Mendoza, José Victoriano Betancourt, llanero, negro curro.

Abstract: The following paper examines Los curros del Manglar o el triple velorio by José Victoriano Betancourt from Cuba, and Un llanero en la capital and Palmarote en Apure by the Venezuelan writer Daniel Mendoza in order to compare and contrast the presentation of marginal characters in Cuban and Venezuelan constumbrista writings of the $19^{\text {th }}$ century. The different urban and political projects that the $19^{\text {th }}$ century elite believed were necessary to build a modern nation - the movement for national hygiene and the importance of rural and peasant wisdom-influenced

AnMal, XLI, 2020, pp. 191-206. 
the introduction of marginal characters as "national subjects" in the national sociopolitical imaginary.

Keywords: costumbrista writings, curro, Daniel Mendoza, José Victoriano Betancourt, llanero.

[...] salió a abrirle un mulato de gigantesca talla, con media nariz menos y tan mal carado, que bastaba verle para recatarle diez años de presidio

José Victoriano Betancourt, Los curros del Manglar o el triple velorio

Palmarote calló... una preñada lágrima rodaba lentamente la mejilla de aquel rostro tostado por el sol y arrugado por las fatigas de una vida rudamente laboriosa

Daniel Mendoza, Un llanero en la capital

El siglo XIX es un periodo de guerras y contradicciones, pero sobre todo lo es de comienzos. En la mayoría de los países de América Latina, al lograr la independencia del imperio español, la clase letrada no sólo siente la necesidad de reorganizar la sociedad e imitar el modo de ser europeo, sino también de identificar aquellos factores tradicionales, rurales y populares que categorizan a su nación como única y que, en algunos casos, luchan contra ese modo de ser extranjero ${ }^{1}$. Es en el siglo XIX cuando se populariza la literatura costumbrista, un género que se traza como objetivo principal el retratar y reflejar los usos y costumbres sociales. En su búsqueda incesante de ese «color local», el autor costumbrista trata de tipificar los rasgos más característicos de una clase social. Para lograr identificar y transmitir lo más autóctono de la cultura al público, los autores latinoamericanos aderezan sus escritos con matices moralizantes y didácticos con la intención de que se utilicen para el camino hacia la civilización y el progreso que tanto deseaban. Los cuadros de costumbre muestran cómo el conjunto de expresiones que conforman a un pueblo y a su historia recrean la cultura colectiva y proyectan al mundo la visión del imaginario nacional.

Parte de ese imaginario nacional también incorpora el retrato de las clases más bajas, de esos otros que viven en los límites de la civilización y por ende del poder económico y social. Ya sea en términos de casta, raza, autoridad o

\footnotetext{
${ }^{1}$ En la introducción a su antología de artículos sobre el costumbrismo, Felipe Martínez Pinzón y Kari Soriano Salkjelsvik discuten la ambigüedad de los autores de cuadros de costumbres a la hora de aceptar o rechazar el modo de ser extranjero (2016: 7-29).
} 
poder, estos sujetos forman parte de los sectores marginalizados y son entendidos como culturalmente inferiores. El propósito de este estudio es examinar cómo difiere la proyección del personaje marginal en el costumbrismo cubano y el venezolano del siglo xix. Fueron José Victoriano Betancourt de Cuba y Daniel Mendoza de Venezuela autores que se aventuraron a esbozar en el imaginario nacional tipos indeseables de la época como gentes maleantes de origen africano o campesinos huraños. Las diferentes contradicciones políticas y económicas que enfrentan ambos países —esas mismas que hacen que Cuba no logre su independencia de España hasta 1898-, y los proyectos específicos que propone la clase letrada para la construcción de cada nación provocan una disímil proyección del otro en las letras costumbristas de Cuba y de Venezuela. Mientras que el personaje marginal de la Isla es retratado como un agente antisocial al que se le teme y debe ser suprimido, el marginal venezolano es reivindicado en los cuadros de costumbres al ser visto como un individuo imprescindible para el desarrollo futuro de la patria. Para analizar la concepción de dichos personajes se tiene en cuenta en este estudio varios aspectos de su descripción que ayudan a determinar su marginalidad: la apariencia física, la manera de hablar, el lugar donde viven y el modus vivendi.

\section{El negro curro, un cubano indeseable en el imaginario decimonónico}

En la literatura costumbrista cubana es la pluma de José Victoriano Betancourt, oriundo de un pequeño pueblo occidental de la provincia Artemisa llamado Guanajay, la que describe a varios personajes de sectores marginales bajo el régimen colonial tales como la vecina pobre, el jugador y holgazán profesional, las viejas curanderas y los negros curros. De sus innumerables artículos de costumbres es, sin lugar a duda, su descripción del negro curro en Los curros del Manglar o el triple velorio publicado en la revista El artista en 1848 una de las que más profundiza en el tema del tipo marginal de la sociedad decimonónica cubana.

En palabras del propio Betancourt, los curros del Manglar son «famosos en los anales de Jesús María por sus costumbres relajadas y por sus asesinatos, que han hecho temblar más de una vez a los pacíficos moradores de los barrios de extramuros» (1941: 131). El curro es un agente racialmente negro que, según el articulista, sobresale por ser extremadamente conflictivo, por poseer una conducta inmoral y un instinto asesino. A diferencia de otros grupos africanos cubanos como los negros ñáñigos y los brujos, el curro nunca fue un negro esclavo y llegó a Cuba no desde África sino desde España, específicamente desde Andalucía. El antropólogo cubano Fernando Ortiz indica que es precisamente esta la gran diferencia y ventaja que tenían los curros sobre otros 
grupos negros que residían en la Isla, quienes incluso hablaban un español con cadencia andaluza que aprendieron en la servidumbre a peninsulares (1986: 8). En la Cuba decimonónica «curro» era sinónimo de «andaluz» pues, como también resalta Ortiz, se les llamaban curros en La Habana porque los primeros en llegar «ya horros y fuera de toda servidumbre, procedieron de Andalucía, de donde vinieron con las chusmas y de las flotas o desterradas de España... quienes imitaron los caracteres de la currería ultramarina y sobre todo sevillana» (1986: 17). En tiempos de esclavitud, el curro era un negro liberto y gozaba de ciertos privilegios, aunque, como se verá a continuación, no de los suficientes como para ser incorporado positivamente en el proyecto de la nación imaginada.

En Los curros del Manglar o el triple velorio, el articulista se propone documentar fielmente todo lo que ocurre en el tercer día del velorio de un niño curro. Lo realmente cautivador de la obra de Betancourt es cómo logra expresar sus reflexiones y observaciones acerca del personaje marginal y su ambiente mientras asume el rol de flâneur caminando por las calles oscuras y peligrosas del hampa cubana. Mas no es por voluntad propia que Betancourt se lanza a describir al curro. Al igual que Mariano José Larra en sus cuadros de costumbres, Betancourt habla de una necesidad que va más allá de la mera curiosidad, una necesidad con el compromiso que tiene el articulista para con los lectores y la profesión pues afirma: «Difícil sobremanera es la misión del escritor costumbrista: observar juiciosamente y copiar con fidelidad los rasgos que modifican este gran cuadro de la vida pública y privada de un pueblo» (1941: 130).

Apenas al comienzo de la narración, mientras se encuentra recostado en un banco bajo la sombra de una ceiba, un amigo le propone la arriesgada aventura: «No sabes cuánto me alegro de haberte encontrado; esta noche vamos a correr una aventura, que, por su originalidad, te prestará materia para un artículo» (1941: 132). Esta búsqueda de material para un artículo, tema común entre los costumbristas, es la excusa perfecta que encuentra el escritor para adentrarse en lo más profundo del hampa cubana y presenciar el triple velorio.

Para despejar dudas de que exista algún vínculo de amistad entre él y los negros curros, el cronista incluye en su narración a un personaje mediador, Esteban, un criollo de la raza blanca. Resulta que su amigo Esteban, ese que le ha invitado a la aventura, es además padrino del negro Timoteo, padre del pequeño curro que falleció hace dos días. Ya sea Esteban un personaje real o ficticio, el articulista parece introducirlo en su narración con el único objetivo de justificar su visita a casa de Timoteo. El autor incluso duda en aventarse al barrio del Manglar porque teme por su seguridad e intenta disuadir a Esteban de abandonar la empresa: «Compadre yo no voy al Manglar; ese es un barrio de los demonios y podemos dejar la piel» (1941: 133), pero Esteban lo 
convence: «No tengas cuidado, que no nos tocarán ni un pelo de la ropa. Timoteo es mi ahijado, como que yo fui quién lo sacó de la cárcel no hace tres meses: allí estaremos más seguros que en la Cabaña: ¿me acompañas, o tienes aún escrúpulos?» (1941: 133). Sin Esteban el narrador jamás hubiera podida presenciar el velorio del parvulito. Concibamos esta relación como una lineal, donde el sujeto A (el articulista), necesita del sujeto B (Esteban) para encontrarse con el sujeto C (los curros). Curiosamente, Esteban no solo conoce muy bien las calles peligrosas del Manglar, sino que también está relacionado con la familia en cuestión por lo que es el vínculo entre los dos mundos: el blanco/letrado y el negro/marginal.

A la hora de puntualizar la fisonomía del curro, Betancourt los asemeja a animales para nada idílicos desvalorizando aún más su estampa. Esa mezcla de lo animal y lo humano que hace que una negra tenga la cabeza deforme «con piel de búfalo» (1941: 136), un aspecto tan maltrecho que luzca bigotes $\mathrm{y}$ «más conchas que una caguama» (1941: 136), y que un negro lleve «largos mechones de pasas trenzadas, cayéndoles sobre el rostro y cuello a manera de grandes mancaperros» (1941: 131) termina brindándole un toque grotesco y casi fantástico a la caracterización. De ahí que la mera descripción del curro ayude a señalar la posibilidad de dos mundos completamente opuestos en la narración, uno blanco y otro negro, donde el sujeto de raza negra, tal y como señala Jorge Camacho, es visto casi como un monstruo o como un demonio (2015: 67).

En cuanto a la vestimenta, el cronista destaca que a pesar de utilizar calzones ajustados blancos o con listas de colores, el curro lleva también otros accesorios como sombreros de paja y argollas de oro. Betancourt asegura además que el negro curro presume de su facha colorida con un «modo de andar contoneándose como si fueran de gonces, y meneando los brazos adelante y atrás» (1941: 131). Esta descripción de la cadencia andante del personaje marginal acentúa no sólo su petulancia, sino también su gallardía o guapería y fundamenta su comportamiento criminal y modo de vida. El personaje que ha decidido plasmar Betancourt, es poco menos que un mamarracho.

Para reforzar la imagen odiosa e inmoral de los curros sin necesidad de intervenir directamente, José Victoriano Betancourt en Los negros curros del Manglar incorpora en su narración varios diálogos entre dichos personajes. De las varias intervenciones dialógicas del cuadro, cinco son protagonizadas por los curros. Primeramente, Timoteo presenta a Esteban ante todos los invitados del velorio. Luego, Timoteo entabla una pequeña conversación con un mulato mientras espera a su padrino - en este caso se trata del padrino de religión, ya que Esteban es su padrino civilmente- Una vez que el padrino llega al velorio, éste, Timoteo y una negra curra también dialogan. Más tarde las vecinas encabezan una disputa de insultos y, para finalizar, tenemos el 
altercado entre el padrino y un curro presidiario que también asiste al tercer velorio del parvulito. Estas pequeñas intervenciones que enriquecen la narración costumbrista brindándole dinamismo y conflicto a su vez tienen como función desprestigiar la moral y las costumbres de esta clase marginal. En el diálogo de las vecinas, por ejemplo, llueven las injurias, las groserías y las vulgaridades: «Oiga uté, ña Critiana, poco a poco con las curras, que lo le han comío su bienmesabe, y tienen mai veigüenza que uté» (1941: 138). El narrador, además, adereza la chabacanería de los curros siempre con un comentario reprobatorio; tal y como ocurre cuando observa con detenimiento las pláticas de los diferentes curros que se acercan a ver al muerto y a dar el pésame a la familia «de más es referir las obscenidades que vomitaban aquellas arpías» (1941: 139).

Sin embargo, no es sino en su poesía costumbrista donde Betancourt logra retratar la jerga curra con detenimiento. Con su décima «El negro José del Rosario», también publicada en el periódico habanero El Artista en 1848, el articulista narra las vicisitudes por las que atraviesa un negro curro llamado José del Rosario y a la par nos regala un arsenal de características lingüísticas que cree propias de este sector marginal, y que sirven para subrayar la función de este grupo como no apto para formar parte del imaginario nacional cubano. De esta manera, se retrata Jesús María así mismo (1941: 11-20):

\author{
Nasí de Jesú María \\ en ei famoso Manglai, \\ fui Perico no hay dudai, \\ y a ningún cheche temía. \\ Conmigo no había tu tia; \\ cuando en cabido o guateque \\ entraba medio peneque \\ y metía la mano al quimbo, \\ hata lo niño de limbo \\ cantaban el turuleque. \\ Yo no conosí repeto \\ ni obedesí capitán, \\ cuando sentía e curricán \\ era mi guto completo.
}

Algunos rasgos del habla curra presentes en estos versos son la confusión con el uso correcto de 1 y $\mathrm{r}$ en medio de sílabas, la ausencia de la $\mathrm{d}$ en palabras con la terminación ido, la sustitución de la r y 1 a finales de sílaba por la vocal i y la omisión de la s al final y en medio de sílabas. El lenguaje es el arma más poderosa que encuentra el letrado decimonónico para trazar esa brecha diferenciadora entre el nosotros (los ricos blancos/criollos de la clase alta) y los 
otros (los negros pobres/esclavos). Incluso en otros géneros en los que el costumbrismo jugó un papel protagónico como son la narrativa y el teatro ${ }^{2}$, el lenguaje es el elemento referencial a la hora de retratar a la clase marginal. Tal y como argumenta Christina Civantos: «Language like race, is seen as part of nature, as an inherited, instructed characteristic, and thus only whites, those of "pure" bloods, have access to pure language» (2005: 59). El uso disparatado tanto semántico como sintáctico del castellano en las producciones literarias del momento parece fortalecer la idea de que ningún negro puede aspirar a un ascenso social dentro del sistema socioeconómico cubano porque es incapaz de incorporar la gramática castellana en un proceso lógico de pensamiento.

No obstante, además de los errores gramaticales, el habla curra presenta otras características que van a sentenciar a este personaje como agente marginal. Al principio del cuadro Betancourt señala que juntamente con la expresión vulgar el curro le da a su voz una «inflexión singular y una locución viciosa» (1941: 131). Y es que, en su manera de expresarse, el curro resalta un exhibicionismo característico. Podemos ver en la décima ya mencionada de El negro José del Rosario cómo el protagonista nos cuenta sus andanzas mientras hace alarde de su guapería y sus dotes de matón. José es un negro cheché. El cheché, tal y como lo fundamenta la narrativa, la poesía y la dramaturgia de esta época, es el cabecilla de la delincuencia negra, el matón entre los matones. Curiosamente, según confirman estudios realizados por Ortiz, la ostentación verbal del curro estuvo grandemente influenciada por el habla del matonismo andaluz (1986: 83).

Como es de esperarse no residían los curros en el centro del progreso, sino en La Habana extramuros, en los márgenes de la civilización del momento. «El área en que operaban los curros, asegura Alberto Yannuzzi, era mayormente La Habana y sus alrededores - Regla, Guanabacoa y Marianao-, pero se afirma que los hubo también en Matanzas, centro en aquel tiempo de la industria azucarera y con una gran población esclava» (2008: 96). Mientras se

\footnotetext{
${ }^{2}$ En Cecilia Valdés de Cirilo Villaverde, por ejemplo, el idioma es el elemento que quizás más determine la subordinación de los personajes negros y mestizos. Visualmente, Villaverde decide señalar la expresión (en este caso bozal) de algunos de sus personajes usando bastardilla. Nótese que las imperfectas intervenciones lingüísticas de Genoveva Santa Cruz, la africana liberta que vende comida por las calles, siempre se presentan escritas en bastardillas: "Me ñama Ginoveve Santa Crú. Mi marío e Tribusio Polanca. Elle tien uno sijo ñamao Malanga que ha sacao mala cabesa. ¡Ha matao ma branco!... Tondálo coge como ratón con quesa le dominga depué de Niño perdío, cuando diba nel entierre de ña Chepa Alarcó" (2004: 572).

Al igual que en Cecilia Valdés, existe en las obras del teatro bufo cubano una necesidad de distinguir el componente lingüístico utilizado por los diversos grupos raciales. En la trilogía Los negros catedráticos de Francisco Fernández no se utilizan las bastardillas ya que no hay necesidad de distanciar a unos personajes de otros porque todos son parte del mismo componente racial, sin embargo, tan importante es el idioma del negro en el teatro vernáculo que se convierte en centro de la acción, desplazando la calidad dramática y el desarrollo de los personajes.
} 
dirige junto a su amigo Esteban a casa de Timoteo, el narrador no puede dejar de documentar la estampa del suburbio «asquerosas pocilgas, donde vivía en mezquinas casuchas una numerosa población casi toda africana» (1941: 133). Betancourt sitúa a sus personajes en el barrio del Manglar, en el seno del hampa cubana y asegura que este albergaba en sus casuchas a «negros, mulatos y blancos sucios, todos asesinos» (1941: 135). He aquí la profesión, el sustento económico y el modus vivendi de los protagonistas de este cuadro: la delincuencia. Una vez en casa de Timoteo el narrador reconoce a Francisco Prieto, más conocido como el Pájaro Verde, un temible delincuente que había cumplido prisión por ladrón y por haber asesinado al menos a seis personas. Irónicamente, la narración culmina con un homicidio. El padrino de religión discute con el Pájaro Verde, y este último le acuchilla a traición. Aterrorizados, el narrador y Esteban se ven obligados a marcharse, no sin antes reconocer todos los peligros a los que se vieron expuestos por observar las costumbres de los habitantes del Manglar, como castigo por tratar de cruzar a un mundo al que no pertenecían.

\section{Palmarote un otro necesario}

En contraste con el papel de los negros curros en el costumbrismo cubano decimonónico, tenemos la proyección del personaje marginal en el cuadro de costumbres venezolano. Aunque con una situación política y social diferente, el estrato inferior de la Venezuela del siglo XIX también queda plasmado en la literatura. A diferencia de Cuba, Venezuela ya había logrado su independencia del imperio español a principios del siglo XIX después de un complicado proceso político que duró dos décadas entre 1810 y 1830. De ahí que los cuadros de costumbres que se analizarán a continuación se centran en la creación del imaginario nacional poscolonial venezolano, en contraste con el cubano.

El personaje marginal en el cuadro de costumbres venezolano aparece en los cuadros de Daniel Mendoza, específicamente en Un llanero en la capital y Palmarote en Apure. A la hora de enmarcar la obra de Mendoza, los estudiosos coinciden que su creación logra desprenderse por completo de las influencias de Mesonero Romanos y Estébanez Calderón inaugurando así el costumbrismo nacional ${ }^{3}$. No cabe duda de que la representación de su personaje Palmarote va a establecer un antes y un después en las letras costumbristas venezolanas. Tal y como Betancourt describe al curro en las letras cubanas, Mendoza introduce al personaje del llanero y así logra elaborar un imaginario

\footnotetext{
3 Pedro Díaz Seijas considera la obra de Daniel Mendoza como parte del primer ciclo del costumbrismo nacional (1980: 423-435). Mientras que Mario Picón Salas la enmarca en la segunda etapa costumbrista venezolana que, según su división, comprende de 1848 a 1864 y es la que logra nacionalizar el género (1980: 5-9).
} 
nacional en donde entran en conflicto los elementos de la dicotomía civilización/barbarie.

El llanero es un tipo oriundo de los llanos de la zona de la cuenca del río Orinoco que comparten tanto Colombia como Venezuela. Es el tipo local mestizo que la clase alta venezolana examina con ojo cauteloso para luego criticar y satirizar. El aspecto racial existe, pues el llanero representa la mezcla de razas, pero en contraste con el cuadro cubano no vemos el conflicto negro con blanco. Nunca hace alusión Mendoza en sus cuadros de costumbres al color de piel del personaje marginal que se dispone a describir. Según el autor, el llanero es un «tipo tan conocido en esta capital, que las pinceladas precedentes bastarían a bosquejado, tipo original e interesante al propio tiempo; tipo, en fin, que difiere esencialmente de los demás caracteres provinciales de aquesta nuestra pobre República» (Mendoza, 1980: 93).

Al analizar el vínculo del narrador con este tipo local podemos apreciar que en Un llanero en la capital existe una estrecha relación entre Palmarote y el doctor en leyes. Palmarote, llanero de Guárico, decide ir a la ciudad a visitar a su amigo el doctor — en este caso el narrador — para que le ayude a resolver un problema legal. Es importante destacar que el doctor identifica al personaje marginal como a su paisano, porque al verle piensa: «Pero, paciencia, me dije, que esta es una de las ventajas del tener paisanos» (1980: 94). En este caso y, a diferencia de Los curros del Manglar, no existe la necesidad de incluir a un tercer personaje para que actué de mediador entre el narrador y el sujeto marginal porque se sabe que Palmarote y el doctor se conocen de antemano, subrayando de ese modo la unión entre el doctor y Palmarote en contraste con la separación entre el negro y el blanco en la obra de Betancourt. Hay que tener en cuenta también que Palmarote ha incumplido la ley. El narrador aclara que Palmarote no se encuentra en la capital por capricho, más bien por un error cometido en Guárico. Aunque este delito desconocido (nunca se revela exactamente qué es) no tacha a Palmarote de delincuente, sí lo hace de ignorante pues es incapaz de resolver esa situación sin la ayuda de su amigo letrado.

Tanto en Un llanero en la capital como en Palmarote en Apure se nos muestra la construcción del otro criollo desde la perspectiva del ojo civilizador y ordenador del letrado citadino, por lo que elementos folclóricos como la vestimenta y el idioma se estereotipan. De esta manera nos describe el autor el atuendo de Palmarote:

Y a propósito, el vestido de Palmarote no dejaba de interesar por su originalidad. Corto el calzón estrecho, terminando a media pierna por unas piezecillas colgantes que remedan, aunque no muy fielmente, las uñas del pavo, de donde toma su nombre, la camisa curiosamente rizada, no abrochado el cuello, ajustada al cinto por una banda tricolor, 
como el pabellón nacional, y cuyas faldas volaban libremente por de fuera: un rosario alrededor del cuello del GUARDA-CAMISA ostentaba sus grandes cuentas de oro; desnudo el pie, y la cabeza, metida por decirlo así, entre un pañuelo de enormes listas rojas, soportaba un sombrero de castor de anchas alas (1980: 95).

Si bien el articulista considera necesario prestarle suma atención a la vestimenta del llanero pues la retrata con gran detalle, más que burlarse del aspecto de Palmarote parece apreciar sus singularidades. Adelso Yánez confirma que «la producción criollista resalta ciertos rasgos culturales de las nuevas naciones latinoamericanas, y para este fin ponía de relieve su diferencia con la cultura europea» (2005: 156). Indiscutiblemente, la manera más fácil de distinguir los contrastes entre la cultura europea y la llanera es describiendo el aspecto físico y la estampa del sujeto marginal. Por su parte, esta caracterización de grandes matices cómicos provoca en el espectador un sentimiento de superioridad ante lo representado o de complicidad con quien está haciendo la broma. Así, la mera descripción de la apariencia del llanero resume dos de los pilares claves del género costumbrista: deleitar y aleccionar.

La dicotomía campo y ciudad, la cual va a reemplazar la pugna entre lo negro y lo blanco del cuadro cubano, se acentúa a medida que el llanero observa con asombro las costumbres de la sociedad capitalina. En casa del doctor, Palmarote fisgonea todo a su alrededor. Hay varios objetos que cautivan su curiosidad: la relojera y el cordón del reloj de bolsillo, el espejo, los guantes, las láminas de los libros, el toilette y los muebles. Mientras los examina, el curioso llanero pregunta por la utilidad de todos estos al doctor, a quien no le disgusta aleccionar a su paisano. Aunque Palmarote en Un llanero en la capital representa la nota discordante en la partitura de la ciudad, el hecho de que el narrador lo inserte en el corazón de Caracas y la civilización del momento constituye el deseo de unir a la ciudad y al campo, espacios vistos como contradictorios, en la concepción de la nación poscolonial.

Como en los dos cuadros de costumbres no hay otros personajes sino el doctor y el llanero, ambos dialogan e intercambian sus opiniones constantemente. Esto a su vez le brinda una gran oportunidad a Mendoza para retratar el habla propia de su paisano en la narración. Una de las características más comunes de esta jerga es el uso de palabras que se derivan del oficio, por ejemplo, Palmarote llama «comedero» a la casa del Doctor, «pedregullales» a las calles principales y «plumario» al letrado. Por su parte, el narrador apunta también otras modalidades lingüísticas de esta clase subalterna como el yeísmo, la confusión de b por gü al principio de sílaba como en «güeno». Otras características visibles son la conservación del sonido de la antigua «h» como en: «jacedores y jumo»; y el errado uso gramatical de la $v$ y la $b$ como en «Berensuela y biene». En su estudio sociológico sobre el llanero, Daniel 
Mendoza señala que el español llanero es además marcadamente andaluz "por sus exageraciones, sus embustes, su propensión a la burla y a la guasa" (1920: 79). Del habla exagerada del llanero tenemos múltiples ejemplos, entre ellos el saludo con el que Palmarote recibe al Doctor en Palmarote en Apure: «jJesús y qué flaco! Lo que le digo es que si lo matan no doy un güevo por la manteca» (Mendoza, 1980: 150).

Es curioso que tanto el antropólogo Fernando Ortiz como Daniel Mendoza hayan puntualizado que el castellano del curro y del llanero sea andaluz. Esto, de cierta manera, hace un guiño a que gran parte de las costumbres negativas que provienen de la madre patria se atribuyen, precisamente, a esa región específica del sur de España perpetuando así un estereotipo negativo que aún vive en nuestros días. En todo caso, todas estas dificultades lingüísticas sumadas a su analfabetismo y a su poco entendimiento de los hábitos y prácticas de la ciudad le impiden a Palmarote comprender en repetidas ocasiones al doctor. Sin embargo, es a través de dichas circunstancias donde el letrado aprovecha para aconsejar y civilizar a su paisano. Labor que no le disgusta.

Al contrario de en Un llanero en la capital, en Palmarote en Apure el letrado decide visitar a su paisano en los llanos. En este segundo cuadro, Mendoza presenta al llanero a sus lectores de la siguiente manera: «Pues para servir a usted, era el ciudadano Palmarote en Apure» (1980: 150). El campesino huraño es nada más y nada menos que un ciudadano con todas sus letras. El folclore del llanero: su manera de vestir, de hablar y todo lo que esto representa es un intento del narrador por incluir positivamente a este agente marginal dentro del imaginario nacional. La inserción y aceptación del otro es la herramienta moderna que propone Mendoza para lograr el tan deseado desarrollo de Venezuela. Tanto así, que ambos personajes invaden el espacio personal del otro. En Un llanero en la capital Palmarote visita en Caracas la casa del letrado y en Palmarote en Apure cuando el doctor da una vuelta por los llanos de Guárico culmina su recorrido en el humilde hogar del llanero sugiriendo, de esta manera, una reconciliación entre dichos sectores sociales tan opuestos. Es en este segundo texto de suma importancia la descripción del articulista acerca del lugar donde vive su paisano:

A la vista de un pueblo libre, porque no obedece hoy a un hombre, sino a la ley, y tranquilo por el hecho de ser libre; a la vista de un pueblo laborioso y feliz, cuanto cabe, sentí ensancharse mi espíritu y abrirse mi corazón a la esperanza (1980: 148-49).

El narrador además de retratar un clima idílico intenta despejar de la descripción de Guárico toda connotación que implique retraso, vulgaridad, ignorancia y peligrosidad. En los llanos que describe Mendoza todos practican la religión del trabajo, no hay protestas en contra de la paz ni del gobierno. 
Nótese también que el uso de la palabra «esperanza» es primordial porque postula una expectativa para la nación venezolana a través de los ideales del campesinado. De ahí que a la concepción placentera de los llanos se le sume la proyección del llanero. El personaje marginal venezolano, a diferencia del curro cubano, es un hombre honrado y humilde, cuyo modus vivendi no es la delincuencia ni la criminalidad, sino el trabajo virtuoso del campo. A diferencia del negro curro, el llanero sí contribuye al florecimiento de la economía nacional por vías favorables. Indudablemente, la estrecha relación entre Palmarote y el doctor sugiere, tal y como alega Bladimir Ruiz, «una apertura del binomio civilización/barbarie que con rigidez e inflexibilidad dominó el análisis de la realidad latinoamericana» (2004: 88).

Cabe ahora preguntarse, ¿por qué se esboza en el imaginario nacional cubano un retrato tan negativo del otro racial/cultural y de una manera tan afable y cordial a Palmarote en el venezolano? En los cuadros de Daniel Mendoza, el llanero es el otro lado de la balanza y representa otro tipo de inteligencia que es necesaria para el funcionamiento de la nación: la inteligencia campesina. En una ocasión, Palmarote cuestiona el sistema de enseñanza alegando que el país menosprecia la educación agraria: «Cuando saben hacer cuatro gasetas, se cren ya unos hombresitos; pero coja usted un Dotor y póngale una soga en la mano, pa que lo bea too regao en siya. Ni sabe apiársele a un toro, ni arriar una madrina, ni trochar una potranca, ni pasar su suya, ni maldita la cosa» (Mendoza, 1980: 104). A lo que el narrador le responde: «iQué disparates, Palmarote! ¿Qué sería si todos fuéramos arreadores de madrinas, como dice usted? Los cultivadores de las ciencias, como los industriales ... todos prestan un gran servicio a la sociedad» (Mendoza, 1980: 105). No es la intención ni del articulista ni de la clase letrada excluir a este tipo social, como lo fue en el caso de los negros curros, sino de integrarlo al proceso de reconstrucción nacional. El crítico uruguayo Ángel Rama expone en la siguiente cita la importancia que la ciudad letrada latinoamericana le otorga al diálogo entre los diferentes estratos sociales para el beneficio y el progreso de la nación:

[...] la ciudad letrada absorbe múltiples aportes rurales, insertándolos en su proyecto y articulándolos con otros para componer un discurso autónomo que explica la formación de la nacionalidad y establece administrativamente sus valores...redescubre las contribuciones populares, localistas, como formas incipientes del sentido nacional y, tímidamente, las contribuciones étnicas mestizadas; sobre todo, confiere organicidad al conjunto, interpretado este desarrollo secular desde la perspectiva de la maduración nacional, del orden y progreso que lleva adelante el poder (1984: 91-92). 
De este modo, ciudad y campo dejan de concebirse como opuestos en los proyectos nacionales. Vemos en esta relación binomial, un vínculo como el del Quijote y Sancho. El doctor y Palmarote, a pesar de ser extremadamente contrarios, se complementan.

En los múltiples diálogos que entablan el letrado y el llanero, se tratan temas que conciernen a la política, a la educación y a la inmigración. En la mayoría de los casos Palmarote no está de acuerdo con lo que plantea su amigo el doctor, como ocurre cuando expone su rechazo acerca de la venida de los inmigrantes europeos. A pesar de que el narrador trata de convencer a su paisano de lo beneficioso que será la llegada de inmigrantes a Venezuela para la economía, Palmarote opina que éstos sólo desean enriquecerse a cuesta del país: «¿Y cómo ha de ser güeno, Dotor, que esos marchantes bengan aquí a yebarse los riales?» (Mendoza, 1980: 102). Es evidente que Palmarote habla físicamente; pero además su habla obtiene estatus dialógico. Esto sucede porque el llanero ocupa en estos dos cuadros una posición discursiva desde la que puede hablarle y responderle al letrado. Con respecto a la libertad de expresión del sujeto marginal, la investigadora Gayatri Chakravorty Spivak afirma en sus estudios sobre el personaje subalterno ${ }^{4}$, que este sujeto no puede en realidad hablar porque el intelectual no le brinda un espacio en el que pueda expresarse. Resalta además que «no debe -ni puede-, en su opinión, hablar "por" el subalterno, ya que esto implica proteger y reforzar la "subalternidad" y la opresión sobre ellos» (Spivak, 2003: 299). Mientras caminan por la ciudad en Un llanero en la capital y sobre todo cuando conversan en la humilde casa de Palmarote en Palmarote en Apure, el escritor costumbrista venezolano intenta escuchar el discurso del llanero. La palabra clave del cuadro es «ciudadano» (Mendoza, 1980: 150), término que califica a Palmarote como perteneciente al concepto de nación, lo que no ocurre en el caso de Los curros del Manglar.

No obstante, esta calidad de ciudadanía es, como fundamenta Ruiz, materializada «solamente en terrenos de la representación simbólica» (2004: 86) y, añadiría yo, representación literaria, porque no le garantiza a Palmarote los mismos derechos que a su amigo el letrado. No tiene acceso Palmarote a la educación y consecuentemente es incapaz, por ejemplo, de llegar a ocupar un cargo importante en el gobierno o trasladarse a vivir a la ciudad. Alejarse de

\footnotetext{
${ }^{4}$ Propuesto por el filósofo marxista Antonio Gramsci, el concepto del subalterno es luego ampliado y enriquecido por "El grupo de Estudios del Subalterno", entre los que se encuentra la investigadora Gayatri Chakravorty Spivak. Spivak reconoce al subalterno "como poseedor de una política de oposición auténtica que no depende de y se diferencia de manera radical del movimiento nacionalista. Para este grupo, "subalterno" se refiere específicamente a los grupos oprimidos y sin voz: el proletariado, las mujeres, los campesinos, aquellos que pertenecen a grupos tribales" (Spivak, 2003: 299).
} 
los confines de los llanos sería transgredir su función de llanero, de «ciudadano» de una sociedad que, por el bien de la modernidad, ha diseñado un lugar específico y un propósito para cada «tipo» de individuo que no debe ser quebrantado si se quiere salvaguardar el orden y la unidad. Finalmente, y para utilizar los términos de Spivack, no tiene el llanero posibilidad de ascender en la escala social para así abandonar de una vez y para siempre su subalternidad. Aunque Mendoza le brinda a su personaje marginal espacio para que exprese sus preocupaciones acerca de los problemas que aquejan a su país e incluso este lo hace desde su punto de vista utilizando su lenguaje y expresión coloquial, Palmarote «no puede en realidad hablar» pues es retratado por el ojo civilizador con el único objetivo de conciliar el diálogo entre campo y ciudad.

En cuanto al retrato del curro, se puede considerar que José Victoriano Betancourt no hace más que esbozar a este tipo bajo los parámetros de la política de saneamiento que se comenzaron a llevar a cabo en la Isla bajo el gobierno del Capitán General Miguel Tacón (1834-1838). Según argumenta la estudiosa de arquitectura Felicia Chateloin, Tacón se propuso reformar la ciudad de dos maneras: impulsando la creación de alcantarillados que sacaran los desperdicios de intramuros a extramuros, y dedicándose a la persecución de agentes indeseables como los maleantes y los vagos (Chateloin citado por Camacho, 2015: 63). El discurso higienista se convierte entonces, en un método que arremete contra la cultura africana. Viéndolo así, no sorprende que el autor sienta vergüenza por haber ido al Manglar y que proyecte en su descripción a los curros como a una raza que se debe eliminar por su improductividad y el daño que causa a la sociedad.

A esto se le suma el famoso «miedo al negro» que sentía la cuidad letrada cubana en el siglo xIx. Tal y como agrega Camacho, la clase dominante teme una sublevación de los negros esclavos influenciados por la revolución de Haití (2015: 13). Debido a la gran populación de esclavos que habitaba en Cuba en el siglo xIX, el «miedo al negro» se alimenta de la imposibilidad que tenían los blancos de deshacerse de los negros porque el origen de su riqueza y bienestar económico provenía de su mano de obra. En 1848 - año en que se publica Los curros del Manglar o el triple velorio - era Cuba aún una colonia española y lo va a seguir siendo hasta 1898. Louis A. Pérez asegura que «Cuban elites could not contemplate the prospects of independence without stopping to consider the economic and cost and political change» (2005: 122). De esta manera, la sociedad cubana finisecular del XIX opera con sistemas ya obsoletos para el resto de Latinoamérica, entre ellos se encuentra el uso de la mano de obra esclava, que no se eliminará hasta $1886 \multimap 6$ años después de haber sido firmado el acuerdo de igualdad de razas en España-. En tiempos de esclavitud, era el curro un negro liberto, factor que justifica la negatividad con que se le describe en el cuadro estudiado y la incapacidad de su inclusión en el 
proyecto de construcción nacional. Betancourt elabora, a través del curro, a un personaje completamente antagónico a las costumbres y a la moral de la clase alta blanca criolla. Siguiendo la línea de pensamiento de Spivack pudiéramos concluir que en Los negros curros del Manglar no se le da voz al curro. Aunque se le retrate con su atuendo propio y con su jerga característica, el propósito de Betancourt es criticar las costumbres curras presentes en el tercer velorio del parvulito. Nunca habla el curro de su condición porque el ojo civilizador no le brinda la coartada.

Si existe una diferencia entre la proyección del llanero y la del curro en las letras costumbristas de Mendoza y Betancourt es que el primero es retratado como un agente quizás folclórico y popular, emblemático de la cultura nacional que debe ser tomado en cuenta, y el segundo como un ser antisocial, indigno de la ciudadanía. Así, en el costumbrismo venezolano se presenta la posibilidad de que existan dos modos de entender el mundo: el de los llaneros y el de los letrados, el del campo y el de la ciudad ${ }^{5}$. Sin embargo, tanto en el caso de Cuba como en el de Venezuela es el letrado, ese quien tiene acceso a la educación y al poder, el que termina manipulando el retrato del otro y lo pinta monstruoso o dócil, improductivo o lucrativo según sus proyectos para la nación imaginada. Ya sea gracias a la iniciativa de saneamiento público o al intento por reconciliar el diálogo entre civilización y barbarie, la proyección de la clase marginal en los cuadros de costumbres de ambos países responde a los proyectos de la clase letrada. La comparación de estos cuadros puntualiza cuán conflictivo fue el proceso de construcción nacional en los diferentes países latinoamericanos durante el siglo XIX. Revisar los errores cometidos en los pasos hacia la tan deseada modernidad de los decimonónicos en cuanto al tratamiento de la clase no letrada o subalterna en general, más que proponer las bases de un legado cultural o histórico ha de servir de espejo a la hora de examinar el estado de la subalternidad actual en dichos países Latinoamericanos.

\section{BIBLIOGRAFÍA}

Betancourt, J. V. (1941): Artículos de costumbres, Publicaciones del Ministerio de educación, Dirección de cultura (Cuadernos de cultura. Quinta serie. 2).

CAMACHO, J. (2015): Miedo negro, poder blanco en la Cuba colonial, Iberoamericana, Madrid.

\footnotetext{
${ }^{5}$ Considérese la relación casi conciliadora que se establece entre civilización y barbarie un siglo después en la novela Doña Bárbara de Rómulo Gallegos publicada por primera vez en 1929. Gallegos, en su propuesta, también opta por una especie de equilibrio entre el folclore del llano y la civilización citadina.
} 
Civantos, C. (2005): «Race, class, language: 'El negro' speaks Cuban whiteness in the teatro bufo», Latin American Theatre Review, pp. 49-69.

DíAZ SEIJAS, P. (1980): «Apéndice: Hacia un concepto del costumbrismo en Venezuela», en M. Picón Salas (ed.), Antología de costumbristas venezolanos del siglo XIX, Monte Ávila Editores, Caracas, pp. 421-435.

MENDOZA, D. (1920): El Llanero (Estudio de sociología venezolana), Editorial América, Madrid.

(1980): «Palmarote en Apure», en M. Picón Salas (ed.), Antología de costumbristas venezolanos del siglo XIX, Monte Ávila Editores, Caracas, pp. 144-177.

(1980): «Un llanero en la capital», en M. Picón Salas (ed.), Antología de costumbristas venezolanos del siglo XIX, Monte Ávila Editores, Caracas, pp. 92-107.

ORTIZ, F. (1986): Los negros curros, Ciencias sociales, La Habana.

PÉREZ, L. A. (2005): Cuba: Between Reform and Revolution, Oxford University Press, New York.

Picón Salas, M. (1980): «Prólogo», en M. Picón Salas (ed.), Antología de costumbristas venezolanos del siglo XIX, Monte Ávila Editores, Caracas, pp. 5-9.

RAMA, A. (1984): La ciudad letrada, Ediciones del Norte, Hanover.

RUIZ, B. (2004): «La ciudad letrada y la creación de la cultura nacional: costumbrismo, prensa y nación», Chasqui: revista de literatura latinoamericana, 33, 2, pp. 75-89. En línea: www.jstor.org/stable/29741883.

SAlKJElSVIK, K. S., y MARTÍNEZ PINZÓN, F. I. (2016): «Prólogo», en Revisitar el costumbrismo: cosmopolitismo, pedagogías y modernización en Iberoamérica, pp. 7-29.

SPIVAK, G. (2003): «¿Puede hablar el subalterno?», Revista colombiana de antropología, 39, pp. 297-264.

Villaverde, C. (2004): Cecilia Valdés o La loma del Ángel, Cátedra (Letras hispánicas).

YÁNEZ, A. (2005): «El diálogo de coplas en la literatura costumbrista de Venezuela: un acercamiento pragmático-lingüístico», Ixquic: revista hispánica internacional de análisis y creación, 6, pp. 152-172.

YANNUZZI, A. (2008): «Los negros curros del manglar según Fernando Ortiz», Círculo: revista de cultura, 37, pp. 94-101. 